\title{
Experimental Research about Self-learning in Technique Acquisition in Sports Dancing-Take Students at Wuhan Physical Education School in Sports Dancing as Example
}

\author{
Yu Mingrong \\ Yaan. Sichuan Agricultural University 625014
}

Keywords: self-learning; sports dancing; technique acquisition

\begin{abstract}
Draw samples from students in grade 2015 from Wuhan physical education school who major in sports dancing, pick out 60 students which include 30 girls and 30 boys, then divide them into two groups called experimental group and control group. There are 30 people in experimental group which consists of 15 girls and 15 boys, 30 people in control group which consists of 15 girls and 15 boys, too. Take self-learning system as independent variables, and the grades of sports dancing promotion game in Wuhan physical education school as reference to make a research about what self-learning does in technique acquisition in sports dancing. The result from independent sample $\mathrm{T}$ shows that the sig number is 0.001 . The experimental group is far better than control group.
\end{abstract}

\section{Introduction}

Self-learning is that students manage their study themselves under the guidance of teachers. For example, definitude the goals of study, make study plans, choose proper study method, enhance the execution and make necessary surveillance, evaluation and adjustment during study process. Self-study covers four parts which are: self-study goals, self-study plans, self-study adjustment and self-study evaluation. The research here adopts experimental methods to explore what impact self-study does in sports dancing technique acquisition to understand the study condition of students who major in sports dancing, to provide reference and advice for students major in sports dancing.

\section{What Self-learning Does to Sports Dancing Technique Acquisition}

Table 1 Independent Samples Test

\begin{tabular}{llllll}
\hline & & F & Sig. & t & df \\
\hline \multirow{2}{*}{ Study grades } & Equal variances assumed & .849 & .361 & 3.370 & 58 \\
& Equal variances not assumed & & & 3.370 & 53.403 \\
\hline
\end{tabular}

Table 1 is the report of independent sample T test analysis, the result is as follows: Number $\mathrm{T}$ of homogeneity of variance row is 3.370 , number sig is 0.001 , the average grade difference of experimental group and control group is number 4.3667, so it has an obvious distinction in technique grade between experimental group and control group, self-learning can make a good impact on learning sports dancing technique.

\subsection{Set a proper study goal and manage it effectively}

\subsubsection{Set a proper study goal}

Study goal is the monitor through the whole study process. If the goal is too high to reach, for it beyond the ability of students, they will feel frustrated after trying, which is not good for students' study, for it will cause the decrease of study self-efficacy. If the study goal is too easy to reach, though students can make it, the process of study will slow down and trigger the decrease of study efficiency indirectly which is also not good for study at end. Sports dancing students should make proper study goals in sports dancing technique study according to their study ability and other 
requirements.

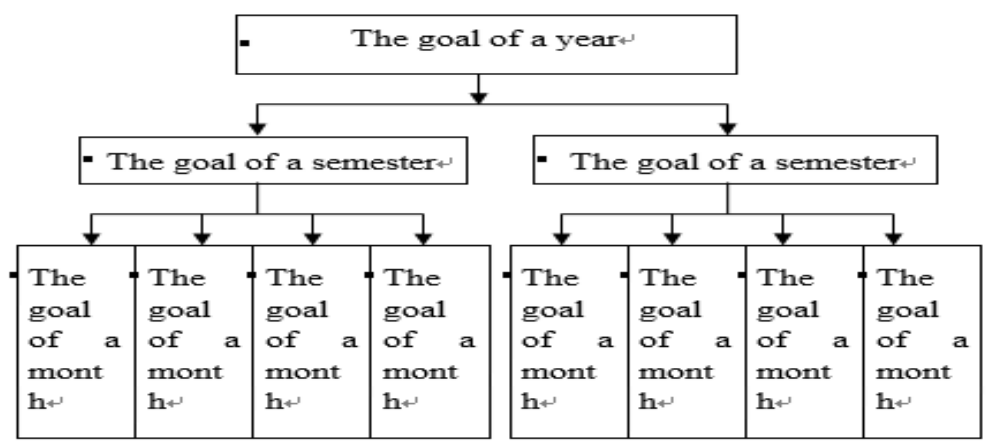

Fig.1 The aim of study

\subsubsection{Manage study goal effectively}

(1) Detailing the final goal and achieve it gradually

In the experience, the picture of aim structure experimental group take is as picture 1 . While we are managing study goal, we can divide sports dancing study goal into four class considering the length of time. The first class goal-the top goal in college, the second class goal-the goal of a year, the third goal-the goal of a semester, the fourth goal-the goal of a month.

(2) Strengthen the connection of each goal

In the whole goal structure picture, these aims are divided into four levels and have connection with each other. The higher level can provide bases for the lower level, the lower level can offer the higher level services.

\subsection{Make study plans and implement them comprehensively}

\subsubsection{Make a feasible study plan}

The goal should be planned and realize it step by step. Study plans should be guided by study goal. We should make a full consideration of the factors both in students themselves and the school to ensure the possibility of implementing the plan. Students major in sports dancing should arrange the study time and tasks properly to achieve the semester's main target in sports dancing. The sports dancing technique study plans of experimental group study task, the method of study and study time.

\subsubsection{Implement study plans and choose varies ways to start studying}

The way of study and independent sample $\mathrm{T}$ test of grade statistical analysis

Table 2 Group Statistics

\begin{tabular}{cccccc}
\hline & Practicing method & $\mathrm{N}$ & Mean & Std. Deviation & Std. Error Mean \\
\hline \multirow{2}{*}{ grades } & 1 & 10 & 77.4 & 4.81202 & 1.52169 \\
& 2 & 10 & 83.2 & 5.39135 & 1.70489 \\
\hline
\end{tabular}

As to the practicing method, 1 presents students who study at school and take lessons with many students at training class out of school and make use of other time to take lessons with few students regularly. The result presents the average grades of students make use of number 1 as the way of study receive scores 77.4. The average grades of students take number 2 as the way of study receive scores 83.2, which are 5.8 scores more than number 1 .

Table 3 Independent Samples Test

\begin{tabular}{cccccccc}
\hline & & & & & & \\
& & $\mathrm{F}$ & Sig. & $\mathrm{t}$ & $\mathrm{df}$ & Sig. (2-tailed) & Mean Difference \\
\hline \multirow{2}{*}{ grades } & Equal variances assumed & .655 & .429 & -2.538 & 18 & .021 & -5.8000 \\
& $\begin{array}{l}\text { Equal variances not assumed } \\
\end{array}$ & & & -2.538 & 17.772 & .021 & -5.8000 \\
\hline
\end{tabular}


Table 3 is the independent sample $\mathrm{T}$ test analysis of two different study method. Compare data in uniform variance column, $\mathrm{t}=0.021<0.05$, which shows that the effect of the two kind of study method can improve the technique level of students better.

\subsubsection{Implement study plans to ensure practice time and finish study task .}

The practice time of art building dancing house in Wuhan physical education school is from 6:00am to 8:00am, 7:00pm to 10:00pm. Open from Monday to Friday. Students have five hours to practice dancing every day, which includes 30 hours a week. Now we identifier students whose practice time is under 5 hours number 1 , students whose practice time is 5 to 12 hours number 2 , students whose practice time is beyond 12 hours number 3, students who don't practice number 4 . We analyze the connection between practicing time and grades by using variance analysis.

Table 4 Multiple Comparisons

\begin{tabular}{|c|c|c|c|c|}
\hline (I) Time & (J) Time & Mean Difference (I-J) & Std. Error & Sig. \\
\hline \multirow[t]{3}{*}{1} & 2 & $-6.5000(*)$ & 2.45515 & .015 \\
\hline & 3 & $-11.8333(*)$ & 2.45515 & .000 \\
\hline & 4 & 2.6667 & 2.45515 & .290 \\
\hline \multirow[t]{3}{*}{2} & 1 & $6.5000\left(^{*}\right)$ & 2.45515 & .015 \\
\hline & 3 & $-5.3333(*)$ & 2.45515 & .042 \\
\hline & 4 & $9.1667(*)$ & 2.45515 & .001 \\
\hline \multirow[t]{3}{*}{3} & 1 & $11.8333(*)$ & 2.45515 & .000 \\
\hline & 2 & $5.3333(*)$ & 2.45515 & .042 \\
\hline & 4 & $14.5000\left(^{*}\right)$ & 2.45515 & .000 \\
\hline \multirow[t]{3}{*}{4} & 1 & -2.6667 & 2.45515 & .290 \\
\hline & 2 & $-9.1667\left(^{*}\right)$ & 2.45515 & .001 \\
\hline & 3 & $-14.5000(*)$ & 2.45515 & .000 \\
\hline
\end{tabular}

* The mean difference is significant at the .05 level.

As chart 4-2 reveals, on the comparison of practicing time to grades, in the first, in the second, in the third, their grades have an obvious difference while under $a=0.05$ level. The grades of the first and fourth have no obvious difference while under a $=0.05$ level.

\subsection{Strengthen self-evaluation and control our study process.}

\subsubsection{Build a self-evaluate system of study}

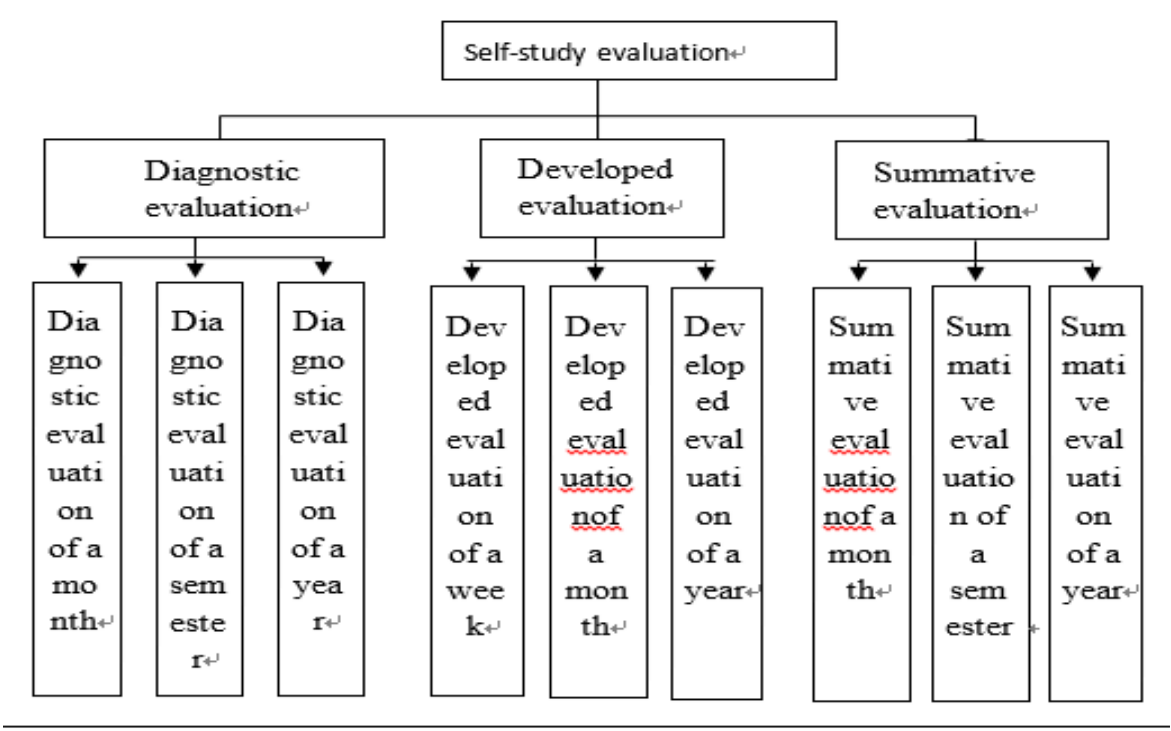

Fig.2 Diagnostic evaluation, Developed evaluation and Summative evaluation.

As we can see in picture 2, in the experiment, the self-evaluation of students take three different 
types and functions to manage it. Diagnostic evaluation, Developed evaluation and Summative evaluation.

\subsubsection{Control study process comprehensively}

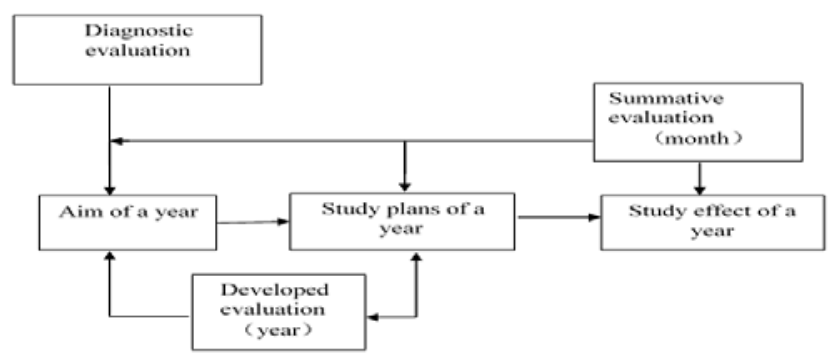

Fig.3 self-study evaluation of a year

In this experiment we take three different types of evaluation (as you can see in picture 3 to 4 ), the shortest time to make self-studying evaluation is one week. In an academic year, we can put diagnostic evaluate into evaluation of a month, evaluation of a semester, the time of developed evaluation is lower than diagnose evaluation, for developed evaluation is happening during studying time, the object is mainly about the process of studying plan and some link which is difficult to implement. Through developed evaluation, we can discover problems in time and correct necessary study plans to improve study efficiency. Summative evaluation includes evaluation of a month, evaluation of a semester and evaluation of the year. Matching diagnostic evaluation to the start stage of study, developed evaluation to the middle stage and summative evaluation to the ending stage is beneficial to ensure them to be useful.

\section{Conclusion}

Though the comparison of the experiment, the students' grades in experimental group have an obvious advantage than control group's. It is mainly reflected in the following four points. First, students who have excellent self-study ability can set study target scientifically and properly. They can detail the study target, divide it into several staged target and correct it in time. Second, students who have excellent self-study ability can make study plan and implement it effectively to ensure the time of practicing sports dancing. Third, students who have excellent self-study ability can make stage evaluation for sports dancing learning and then check and think about it so that they can correct study plans constantly and perfect the self-study system. Fourth, students who have excellent self-study ability are good at controlling study process, and they can overcome difficulties in study process with strong willpower. They also do well in feeling control to handle conflict between dancing partner.

\section{References}

[1] Han Lu. The research of ways to promote the self-study of students in the web environment [D] Hebei. Hebei University 2010.6

[2] Han Xianghua. English self-study ability survey and treatment research of medical adult student [J].Chinese adult education, 2010.4, 180-181.

[3] Zeng Chunmei. Self-study exploration under new lessons [D].Fujian. Fujian teacher training college.2004.6 